\title{
Nanotechnological and energy-saving methods of production of building composites
}

\author{
Olena Shynkevych ${ }^{1, *}$, Yevgen Lutskin ${ }^{1}$, Oleksandr Koishev $^{1}$, Georgiy Bondarenko ${ }^{1}$, \\ Andriy Tertychnyi ${ }^{1}$, and Igor Myronenko ${ }^{2}$ \\ ${ }^{1}$ Odessa State Academy of Civil Engineering and Architecture, Didrikhson st. 4, 65029 Odessa, \\ Ukraine \\ ${ }^{2}$ Odessa National Maritime University, Mechnikov st. 34, 65029 Odessa, Ukraine
}

\begin{abstract}
The bases of silicate materials' manufacture of non-autoclave hardening are developed. The realisation opportunity of technological decision complex of using of mineral substances' structure in silicate materials' manufacture of non-autoclave hardening and wall's products on their basis is theoretically proved and practically confirmed. The complex activation of mixture with water materials, as slip, defined the transition from autoclave treatment to thermo-moisture one of silicate materials. The possibility of the practical realization of structure mineral substances' reserve for the energy consumption of silicate material production are proved experimentally. The optimization of the composition and the hardening conditions in the conditions of thermo-moisture treatment on the basis of experimentally-statistical modelling ensured the receipt of materials with the required properties. The analysis connection between hardening conditions and contents has been fulfilled on experimentalstatistic models. The changing of silicate materials' properties under the influence of inorganic modifier' surface, of hardening conditions and content of gypsum addition have been estimated. Correlation analysis allows to receive new information about the influence of the contents and the hardening conditions on a degree of interrelation between the structure and the properties of building materials. Optimal compositions and the regimes of hardening are recommended for the receipt of wall's articles of a different purpose.
\end{abstract}

\section{Introduction}

Development and introduction of the energy conservation and competitive building materials are the actual question of building branch. In these conditions the normative requirements to heat-protection of constructions increase considerably. Substantial increase of production volume of heat-effective building materials is planned.

In total amount of wall material productions the significant volume is allocated with silicate materials, as effective and ecologically pure materials. Production of silicate

* Corresponding author: elena_shinkevich@ukr.net 
concrete has reserves on decrease of bulk density, heat conductivity and charge of material and energy.

Within these problem the production with using of modern technology process equipment the wall's silicate non-autoclave hardening materials and their optimization on a complex of quality parameters, first of all the heat conductivity, is a perspective direction which will allow to reduce expenses of energy as at a stages of materials and articles' production, and at a stage of construction operation.

The production's opportunity of silicate materials non-autoclave hardening due to use active silica has been proved with positions of thermodynamics in works $[1,2]$.

The production's opportunity of silicate materials at normal temperature and pressure $\left(\mathrm{T}=85 \pm 2^{\circ} \mathrm{C}, \mathrm{d}=0.1 \mathrm{MPa}\right.$ ) allows to speak about essential potential reserves of production of this kind of articles $[3,4]$.

\section{Technological bases of reception of silicate materials of non- autoclave hardening}

On the basis of experimental-theoretical researches the opportunity of realization of the non-autoclave technologies of silicate materials' reception is established. Hydrated limesilica binding substances at temperature $\mathrm{T}=85^{\circ} \mathrm{C}$ and atmospheric pressure is realized due to high index $\mathrm{pH}$ with using as components binding not slaked to exhaust, which is grounded together with quartz sand, and chemically active amorphous silica with the optimum specific surface, which is entered instead of the ground quartz sand's part.

The necessity of calcium hydroxide's linkage in autoclave processing conditions is caused by chemical thermodynamics of lime and quartz: with rise in temperature the solubility to exhaust falls, though the speed of dissolution increases, and the solubility of silica increases (fig.1.) [5]. Under certain conditions synthesis of hydrosilicates of autoclave hardening is possible at temperature below $100^{\circ} \mathrm{C}$ and atmospheric pressure $[1,2,6]$.

a)

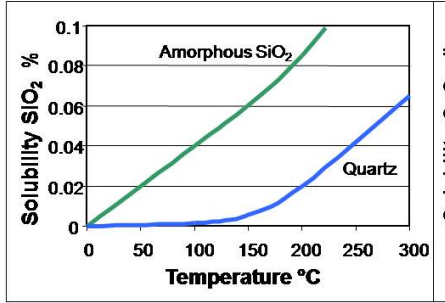

b)

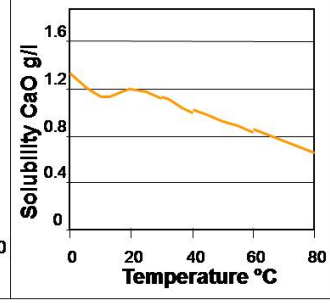

c)

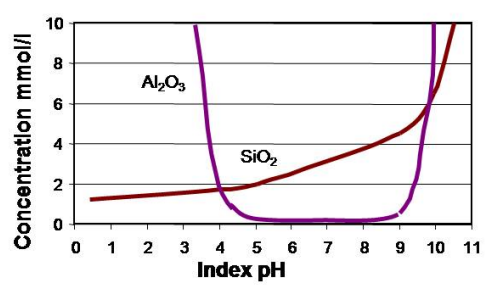

Fig. 1. Influence of temperature midst on solubility of silicate concrete mixture components: $\mathrm{SiO}_{2}$ (a) (J.Shtark), $\mathrm{CaO}$ - (b) (V.Babushkin, O.Mchedlov-Petrosyan) and an index $\mathrm{pH}$ on concentration of $\mathrm{Al}_{2} \mathrm{O}_{3}$ and $\mathrm{SiO}_{2}$ - (c) (J.Shtark).

With regulation of lime speed and silica dissolution it is possible to displace balance in system in this or that side and to change kinetic of hydrations and properties of silicate materials.

The technology provides complex activation of a silicate concrete mixture, including a fine-grained filler, warming up a mix in forms at a stage of preliminary ageing and thermomoisture treatment $(\mathrm{TMT})$ at $\mathrm{T}=85^{\circ} \mathrm{C}$. The preliminary moderate warming up a mix in forms is provided by application of not slaked ground lime together with quartz sand. Speed regulation of lime's thermal emission is provided by the optimum water-firm relation, the content of gypsum additives and plasticizer [7].

Thermal activation of components of a silicate concrete mixture is traditionally carried out in autoclaves where under the conditions of the raised temperature and pressure there is 
a hydrothermal synthesis of calcium hydrosilicates (V.Mihaelis). Transition from hydrothermal synthesis of hydrosilicates of calcium in autoclaves to thermo-moisture processing is carried out due to association of the following ways of activation:

- mechano-chemical activation of crystal quartz in an aquatic midst of the mixeractivator,

- chemical activation - due to introduction of the inorganic modifiers, containing amorphous silica, and the raised values $\mathrm{pH}$ midst,

- thermal activation - due to application of not slaked ground lime.

\section{Nanotechnology receptions of producing the complex activated composites on silicate matrix}

Developed by the authors the complex activation includes the continuous loop of the different types and methods of activation: mechanical, chemical and thermal $[6,8,9,10]$. Each type of activation is accompanied by effects which create the conditions for the possibility of subsequent type of activation.

The result of the complex activation is the formation of linear defects, dislocations and point positions and substitutions. Furthermore, there may be angle changing between the bonds and the appearance of dangling bonds, which leads to the formation of free radicals in the crystals with covalent bonds and the amorphization for molecular crystals.

Each type of activation will be caused by the prevalence of any type of deformations of the solid phase structure. The differences will be responsible for the nature and kind of dislocations with allowance for the extent and duration of external and internal influences.

\subsection{Mechanical activation.}

Mechanical effects in the dispersion medium speed mixer activator provide mechanochemical activation of crystalline quartz surface. The term "mechanochemical reaction" was introduced by W.Ostwald in 1891.

Mechanochemical activation is carried out to the special properties of the newly formed surfaces, especially changing the local chemical and phase content of solids, as well as their aggregate state under the influence of mechanical effects of high intensity.

As nanotechnology reception the mechanochemical activation reduces the viscosity of 3 or more dispersed system containing lime $[6,8,9,10,11]$. This effect of viscosity reducing was used to compensate the increased water demand of the mixture introducing the composite porous opal-cristobalite rocks and using the activation of the binder together with the fine aggregate.

\subsection{Thermal activation.}

Using as a binder quick lime promotes the "inner activation" of dispersed system under an elevated temperature $\mathrm{T}=40 \div 60^{\circ} \mathrm{C}$, the formation of multiple point contacts in the dislocation fields are appeared and the conditions for the hydration hardening unrelated in hydrous calcium lime are created.

External thermal activation occurs in conditions of thermal-moisture treatment. In such conditions at $\mathrm{T}=85^{\circ} \mathrm{C}$ contradiction is canceled, which is connected with the increasing the quartz solubility and decreasing lime solubility with increasing its dissolution $[2,4]$. In addition, the increase of $\mathrm{pH}$ system causes to create favorable conditions for longevity growths GSK during the operational phase when $11.5 \leq \mathrm{pH} \leq 12.5$. 


\subsection{Chemical activation.}

According to E. Avvakumov's works [12] with the presence of water in the inorganic solid-phase system "method of soft mechanochemical synthesis" is happened. To obtain composite oxides from the simple oxide hydroxides are used as the starting components one of which is characterized by acidic, the other one is characterized by basic properties. By means of the neutralization reaction the intensification of the processes takes place. In addition, in such system the conditions for the hydrothermal processes are created.

The acid activation occurs by introducing the amorphous-crystalline silica, alkaline activation - the introduction of increased amounts of lime; it raises $\mathrm{pH}$. The replacement of ground quartz sand in the binder by opal-cristobalite rocks enhances to increase frost and water resistance of the silicate matrix while reducing its density matrix to $20-25 \%$.

Moreover, the presence of opal-cristobalite rock in the dispersion causes formation of nanoscale in the GSK pores of these rocks; in this case they are "nanoreactor"; which walls restrict the growth of neoplasm [13]. Also, the presence of particles of porous rocks with different dispersion binder allows adjusting the speed and reaction kinetics of hydration [6, $8,9]$.

The use of quick lime determines the possibility of using of high modulus liquid glass as one of the alkali addition, so the temperature rise on the forming stage allows regulating rapid setting of such mixture.

Alkali and alkali-containing additives increase the thermodynamic instability of systems by shifting the equilibrium caused by the formation of additional defects on the surface of silica-containing components. Alkali-containing additives are capable to aeration of mixtures under the certain conditions [14].

In this work, the low-temperature aeration of concrete during introduction of the activation to the mixture for the silicate matrix by liquid glass additives $\mathrm{Na}_{2} \mathrm{O} \cdot \mathrm{nSiO}_{2}+\mathrm{mH}_{2} \mathrm{O}$ and sodium hydroxide $\mathrm{NaOH}$ was provided.

\section{Experiment}

The select of the plan and factors for experiment is carried out in the view of following positions. The inorganic modifier with the set specific surface carry out a role of modifiers of structure and allow to regulate a kinetics of hydration and structurization processes [10, $11,12,13]$. Depending on a specific surface of inorganic modifier, reaction can go in conditions of lime's excess, deficiency or at its full linkage.

The basic natural experiment is realized on sated to 24 punctiform six factors plan of type MTQ "mixture-technology-quantity" [15, 16, 17]. The specific surface of the inorganic modifier was fixed as three dependent mixture factors at levels: $v_{1}=\mathrm{S}_{\mathrm{sp} 1}=350 \mathrm{~m}^{2} / \mathrm{kg}$, $\mathrm{v}_{2}=\mathrm{S}_{\mathrm{sp} 2}=425 \mathrm{~m}^{2} / \mathrm{kg}, \mathrm{v}_{3}=\mathrm{S}_{\mathrm{sp} 3}=500 \mathrm{~m}^{2} / \mathrm{kg}$. The factors are connected by linear dependence: $v_{1}+v_{2}+v_{3}=1$. The duration of a preliminary ageing ( $\tau_{\text {p.a. }}=0 \div 12$ hours $)$, duration of TMT ( $\tau_{\mathrm{TMT}}=10 \div 18$ hours) at $\mathrm{T}=85^{\circ} \mathrm{C}$ and contents of the additive of gypsum $\left(\mathrm{C}_{\mathrm{g}}=0 \div 5 \%\right)$ were changed as three independent factors. In each point of the plan there were generated on 15 identical structures. By the plan it is calculated two identical complexes of six-factorial experimentally-statistical models by type (1) $[15,16,17]$. The models describe dependence "content-technology-properties" and "content-technology-structure". It has allowed to study dependence "characteristics of structure- properties".

The results of physical and chemical researches have shown a presence in structure of hydrosilicates of calcium of different sorts, morphology and quantities depending on a specific surface of the inorganic modifier, the contents of the additive of gypsum and hardening conditions. By the results of electronic microscopy, DTA and X-ray 
hydrosilicates of calcium of are identified: hillebrandite B, its version hillebrandite $\mathrm{C}$, foshahite and partially crystal CSH (II) $[6,8,9]$.

The frost resistance of monomineral samples of hillebrandite (F100) is on the order above, than frost resistance CSH (B) (F10) and to bermorite (F15) which form mainly firm phase of autoclave materials $[1,2]$.

\section{Results and discussion}

By results of experiment experimentally-statistical models of influence of contents and conditions of hardening on properties and characteristics of structure of silicate materials of non-autoclave hardening are calculated.

The models of change of a porousness of the general, opened and closed, and also the quantitative contents of hydrosilicates of calcium under influence of six factors are calculated. The changing of the general porousness on $10 \%$ the relation of opened porousness to closed porousness increased in three times. Character of a capillary porousness was estimated by the relative average size of capillaries $\left(\mathrm{d}_{\mathrm{k}}\right)$ which changes in 4.4 times and by the coefficient of uniformity of distribution of sizes of capillary pores $\left(\alpha_{k}\right)$ which changes in 2.5 times.

The contents and hardening conditions which provide a maximum of compressing strength do not coincide with values of these factors which provide a minimum of heat conductivity or a maximum of frost resistance. So, under influence of all six factors the increase compressive strength calculated on a full ES model, makes 6.4 times. Joint influence on compressive strength of three groups of factors: grain-growing content $\left(\mathrm{S}_{\mathrm{sp} 1}\right.$, $\mathrm{S}_{\mathrm{sp} 2}, \mathrm{~S}_{\mathrm{sp} 3}-$ the block D), hardening conditions $\left(\tau_{\mathrm{TMT}}\right.$ and $\tau_{\mathrm{p.a}}-$ the block $\left.\mathrm{B}\right)$ and additives of gypsum $\left(\mathrm{C}_{\mathrm{g}}\right)$ in quantitative expression is equivalent. Each group of factors is able to provide a gain of compressive strength more than twice (fig. 2.).

Table 1. The relative modification of the properties under the influence of the different groups of factors technology and content

\begin{tabular}{|c|l|c|c|c|}
\hline & \multicolumn{1}{|c|}{ Groups of factors } & $\mathbf{R}_{\mathbf{b}}$ & $\mathbf{F}$ & $\boldsymbol{\lambda}$ \\
\hline 1. & The various specific surface area $\mathrm{S}_{\mathrm{sp}}$ of the inorganic modifier & 2.1 & 2.5 & 1.6 \\
\hline 2. & The hardening conditions $\tau_{\text {p.a. }}, \tau_{\mathrm{TMT}}$ & 2.1 & 1.0 & 1.5 \\
\hline 3. & The additive of gypsum $\mathrm{C}_{\mathrm{g}}$ & 2.2 & 2.0 & 1.0 \\
\hline 4. & All six factors $\mathrm{S}_{\text {sp }}, \tau_{\text {p.a. }}, \tau_{\mathrm{TMT}}, \mathrm{C}_{\mathrm{g}}$ & 6.4 & 4.8 & 3.0 \\
\hline
\end{tabular}

Table 2. The value of the specific surface of the inorganic modifier $S_{\mathrm{sp}} \mathrm{m}^{2} / \mathrm{kg}$, wich provide the optimum properties

\begin{tabular}{|l|c|c|}
\hline & Without gypsum & With gypsum \\
\hline $\mathbf{R}_{\mathbf{b}} \mathbf{m a x}$ & $\mathrm{S}_{\mathrm{sp} 2}=425$ & $\mathrm{~S}_{\mathrm{sp} 1}=350$ \\
\hline $\mathbf{F} \mathbf{m a x}$ & \multicolumn{2}{|c|}{$0.5 \mathrm{~S}_{\mathrm{sp} 1}+0.5 \mathrm{~S}_{\mathrm{sp} 3}$} \\
\hline$\lambda$ min & $\mathrm{S}_{\mathrm{sp} 1}=350$ & $\mathrm{~S}_{\mathrm{sp} 3}=500$ \\
\hline
\end{tabular}




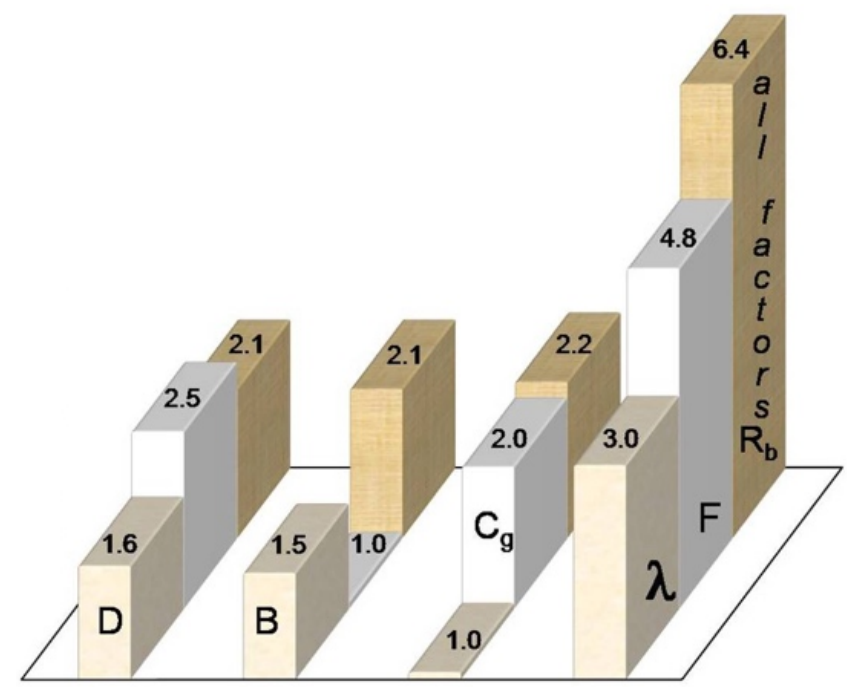

Fig. 2. The analysis of relative influence of various groups of factors: grain-growing content $\mathrm{S}_{\mathrm{sp} 1}, \mathrm{~S}_{\mathrm{sp} 2}$, $\mathrm{S}_{\mathrm{sp} 3}$ (the block D), the hardening conditions $\tau_{\mathrm{TMT}}$ and $\tau_{\text {p.a. }}$ (the block B), additives of gypsum $\left(\mathrm{C}_{\mathrm{g}}\right)$ and their interactions (a full model) on a coefficient of heat conductivity $\lambda$, a frost resistance $F$ and a compressive strength $\mathrm{R}_{\mathrm{b}}$.

The coefficient of heat conductivity $\lambda$ changes in three times depending on a specific surface of the inorganic modifier and hardening conditions: $0.43-1.3 \mathrm{Wt} / \mathrm{m} \cdot \mathrm{K}$. So, under influence of a specific surface of a inorganic modifier the relative change of a coefficient of heat conductivity equal 1.6 (the block D), under influence of hardening conditions - 1.5 (the block B). what is connected to the relative average size of capillary pores $d_{k}$ changes in 6 times (a correlation coefficient $\mathrm{r}\left\{\lambda ; \mathrm{d}_{\mathrm{k}}\right\}=0.68 \div 0.89$ ) and coefficient of uniformity of distribution of sizes of capillary pores $\alpha_{k}$ - in 2 times (a correlation coefficient $r\left\{\lambda ; \alpha_{k}\right\}=-$ $0.75 \div-0.91)$. 

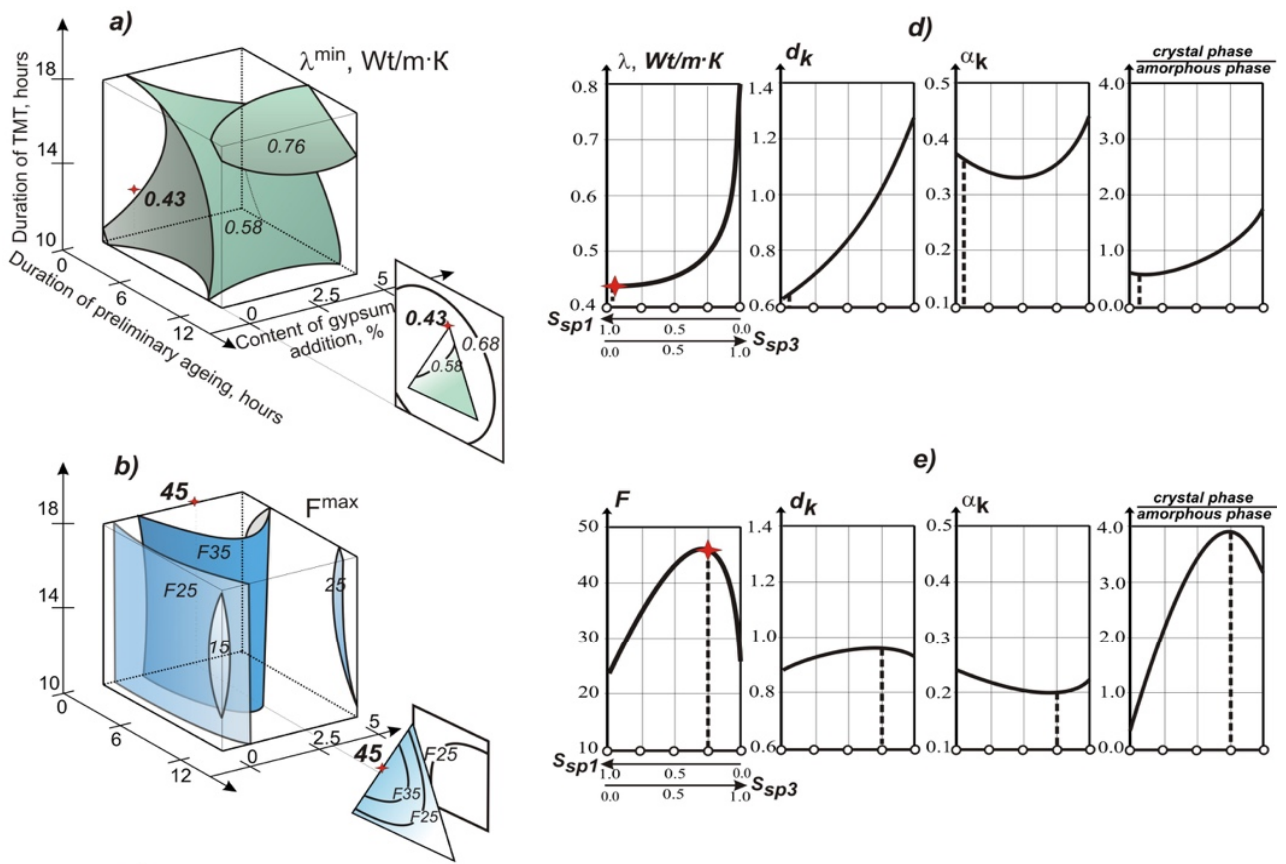

e)

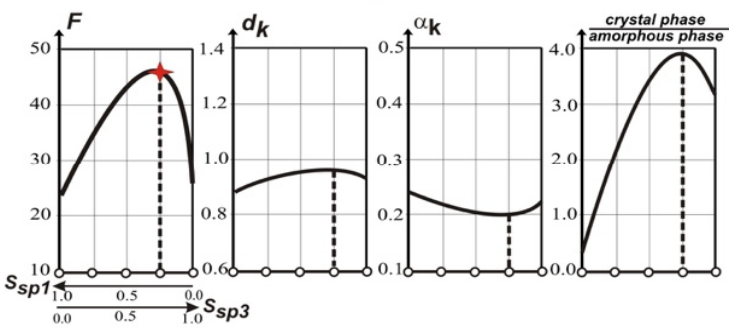

c)

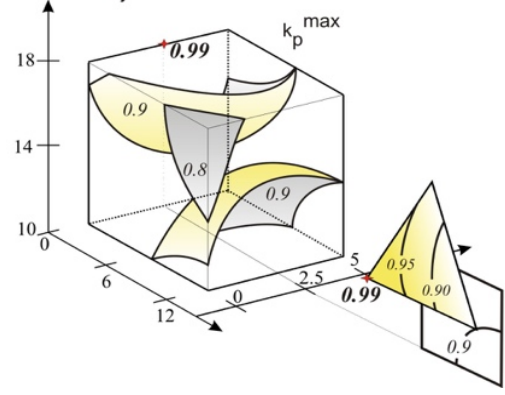

f)

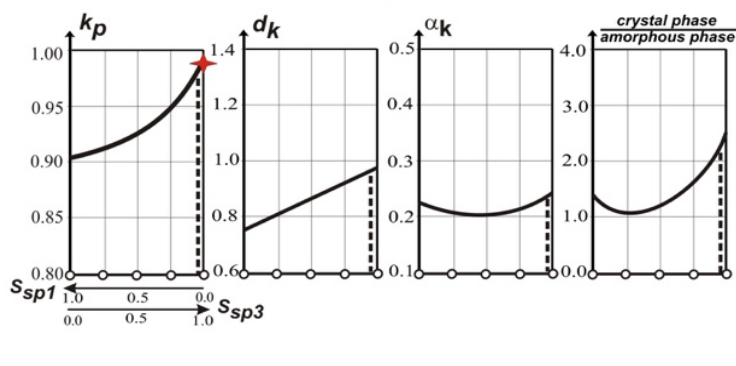

Fig. 3. The change of a coefficient of heat conductivity (a), of a frost resistance (b), of a coefficient of water resistance (c) under influence of hardening conditions and contents of the additive of gypsum at optimum values of size of a specific surface of the inorganic modifier $\left(\lambda^{\text {min }}, \mathrm{F}^{\text {max }}, \mathrm{k}_{\mathrm{p}}{ }^{\max }\right.$ accordingly) (isosurfaces are inside the cube - a full model); hardening conditions at the fixed contents of gypsum (isolines on the squared diagrams - the block B); a specific surface of the inorganic modifier at the fixed values of hardening conditions and the contents of gypsum (isolines on the three-cornered diagrams - the block D). Influence of content of inorganic modifier $\mathrm{S}_{\mathrm{sp} 1}$ and $\mathrm{S}_{\mathrm{sp} 3}$ on the relative average size of capillary pores $\mathrm{d}_{\mathrm{k}}$, coefficient of uniformity of distribution of sizes of capillary pores $\alpha_{\mathrm{k}}$ and a ratio of crystal phase and amorphous one for the optimum hardening conditions and the contents of the additive of gypsum $\left(\lambda^{\min }-(d), F^{\max }-(e)\right.$ and $\left.k_{p}^{\max }-(f)\right)$.

The great value for a coefficient of heat conductivity has also a ratio between amorphous and crystal phases in cementing substance. This ratio changes more than ten time. The coefficient of heat conductivity of crystal quartz two times more than of amorphous silica. Downturn of density on $20-25 \%$ as a result of increase in a share of the closed porosity of the inorganic modifier also causes decrease in coefficient of heat conductivity.

Due to the additive of plaster at constant size of coefficient of heat conductivity $\lambda$ the compression strength increases more than twice. 
It enables receptions of wide scale of composites with a complex of differing properties. The specific surface of the inorganic modifier (the block D) influences on a frost resistance 2.5 times more, than hardening conditions (the block B). Character of a porousness for a maximum of frost resistance $F$ and a minimum of a coefficient of heat conductivity $\lambda$ is various: the relative average size of capillaries $\mathrm{d}_{\mathrm{k}}(\mathrm{F})=0.95>\mathrm{d}_{\mathrm{k}}(\lambda)=0.85$ and the coefficient of uniformity of distribution of sizes of capillary pores $\alpha_{k}(F)=0.2<\alpha_{k}(\lambda)=0.38$ (fig.3). Increase of frost resistance is provided due to formation in structure of additional contacts from the particles of secondary quartz.

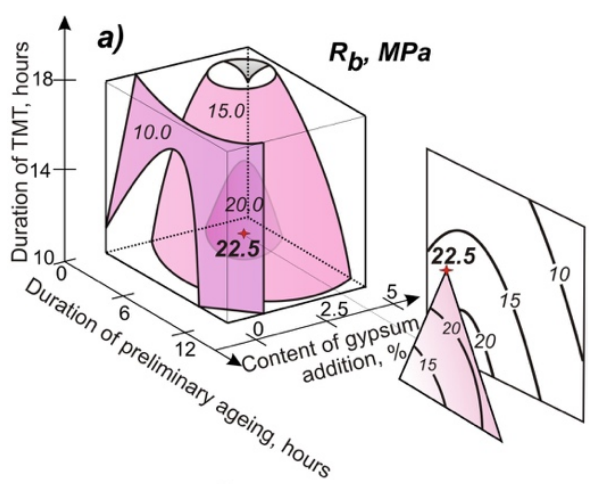

c)

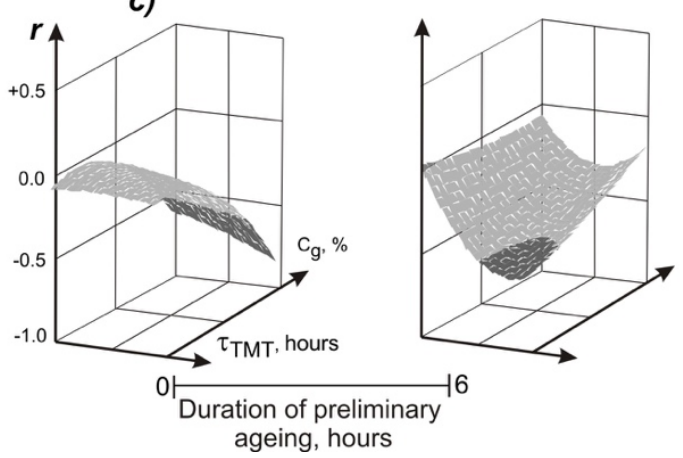

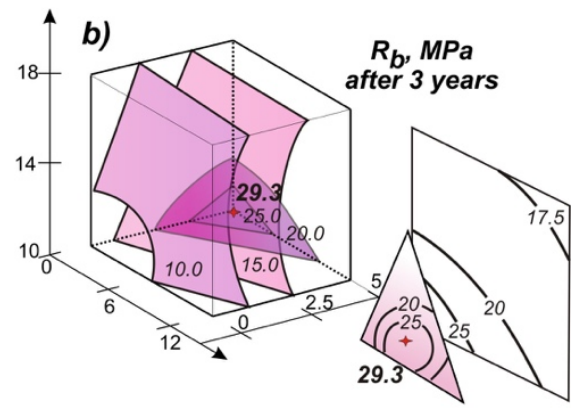

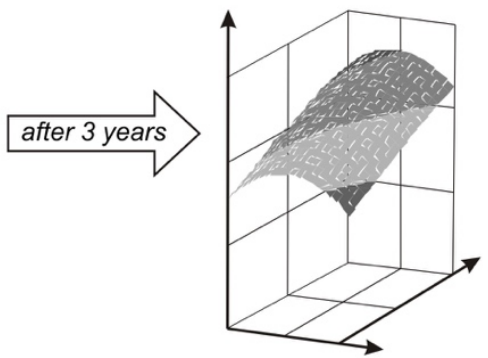

Fig. 4. The change of compressive strength after TMT (a) and age of $3 \mathrm{~d}$ years (b) under influence of hardening conditions and contents of the additive of gypsum at optimum values of size of a specific surface of the inorganic modifier $\left(\mathrm{R}_{\mathrm{b}}{ }^{\mathrm{max}}\right)$ (isosurfaces are inside the cube - a full model); hardening conditions at the fixed contents of gypsum (isolines on the squared diagrams - the block B); a specific surface of the inorganic modifier at the fixed values of hardening conditions and the contents of gypsum (isolines on the three-cornered diagrams - the block D). The coefficient of correlation $\boldsymbol{r}$ between $R_{b}$ and the ratio of amorphous and crystal phases at various stages of processes of hydration and structurization (c).

Increase of frost resistance is promoted by formation in structure of additional contacts from particles of secondary quartz. Crystallization of amorphous silica blocks capillaries on their length. The additive of gypsum changes a coefficient of uniformity of distribution of sizes of capillary pores $\alpha_{\mathrm{k}}$ with 0.6 till 0.85 . The estimation of effects of interactions between parameters of structure and properties on the blocks of experimental-statistic models allows to define the most sensitive to regulation of the characteristic of structure. The value of interrelation between characteristics of structure and of properties is changing in the time as a result of spatial changes of parameters of structure. It is shown the various contribution of a characteristics of structure in formation of properties at different stages of process of structurization, for example on the compressive strength (fig. 4). 


\section{Conclusion}

The bases of manufacture of lime-silica composites (non-autoclave hardening) are developed.

The complex activation of high-mobility silicate concrete mixture, including finegrained filler, provides transition from autoclave processing to thermo-moisture treatment at $\mathrm{T}=85^{\circ} \mathrm{C}$.

Technical and economic calculation has shown, that transition from autoclave processing of the products received by a method of pressing to thermo-moisture treatment processing of products, reduces expenses for manufacture more than $25 \%$; and introduction of wall's products allows to reduce a heat consumption through non-load-bearing designs to $30 \%$.

The contribution of various characteristics of structure to formation process of properties changes in the time.

The kinetics of hydration processes and structurization can be adjusted by a specific surface of the inorganic modifier, defining individual levels of properties. Influence of content, in particular of specific surface of the inorganic modifier, and hardening conditions on various properties in quantitative expression is ambiguous.

\section{References}

1. O.P. Mtschedlov-Petrosyan, V.I. Babuschkin, Poc. $4^{\text {th }}$ Int. Symp. Chem. Cem, 1, 533544 (1960)

2. V.I. Babushkin, O.P. Mchedlov-Petrosyan, Silicate Waterproof Products (Kiev, 1962)

3. V.I. Bolshakov, A.I. Golovko, A.V. Koval, Yu.I. Mustafin, S.A. Sherbak, Structurization of the silicate systems (Dnepropetrovsk, 2000)

4. J. Shtark, B. Viht, Durability of Concrete (Kiev, Transl. from German, 2004)

5. H. Taylor, Chemistry of Cement (Moscow, the World, 1996)

6. E. Shinkevich, N. Sidorova, E. Lutskin, V. Sidorov, S. Politkin. Raw Mix for Obtain Modified Silicate Materials and Method of Its Prepare. Declared patent 64603 A, 7 C04B28/20, Ukraine (2004)

7. P. Krivenko, Proceeding of International Conference "Alkali Activated Materials Research, Production and Utilization", 313-332 (2007)

8. E. Shinkevich, E. Lutskin, O. Gnyp, A. Koichev, J. Dotsenko, Proceeding of the 8th Int. Symp. Brittle Matrix Composites 8, 517-525 (2006)

9. E. Shinkevich, Proceeding of 13th Int. Congress on the Chemistry of Cement, 351-358 (2011)

10. Y. Lutskin, E. Shinkevich. Proceeding of 14th Int. Congress on the Chemistry of Cement, 2, 632 (2015)

11. E. Shinkevich, Y. Zaytsev, E. Lutskin, G. Bondarenko, A. Tymnyak, Proceeding of 2nd International conference on Microstructural-related Durability of Cementitious Composites, 1462-1468 (2013)

12. E.G. Avvakumov, M. Senna, N. Kosova, W. Soft, Mechanochemical Synthesis a Basis for New Chemical Technologies (Netherlands, Kluwer Academic Publishers, 2001)

13. C. Poole, F. Owens, Nanotechnology (Moscow, Technosphere, 2005)

14. V.D. Gluhovskij, R.F. Runova, S.E. Maksunov, Binders and composite materials of contact hardening (Kiev, Budivelnik, 1991) 
15. V. Voznesenskiy, T. Lyashenko at al., Computer and optimization of composite materials (Kiev, Budyvelnik, 1989)

16. E. Lutskin, E. Shinkevich, Proceeding of 13th International Congress on the Chemistry of Cement, 359 (2011)

17. E. Lutskin, E. Shinkevich, Technical Journal, 9 (1-2015), 27-33 (2015) 